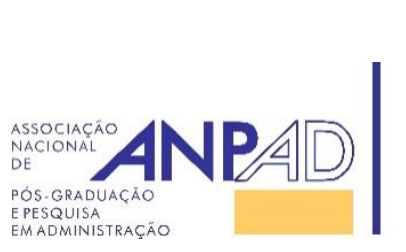
Disponível em
http://www.anpad.org.br/rac
RAC, Rio de Janeiro, v. 21, Edição Especial FCG, art. 3, pp. 41-62, Abril 2017

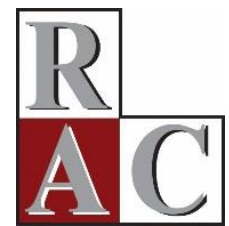

\title{
A Escolha de Fundos de Ações e o Investidor Individual
}

\author{
Stock Fund Selection and the Individual Investor
}

\author{
João Antonio de Mendonça Júnior ${ }^{1}$ \\ Carlos Heitor Campani ${ }^{2}$ \\ Ricardo Pereira Câmara Leal ${ }^{2}$
}

Quantum Finance ${ }^{1}$

Universidade Federal do Rio de Janeiro/Instituto Coppead de Administração

Artigo recebido em 16.02.2016. Última versão recebida em 16.05.2016. Aprovado em 17.05.2016. Publicado online em 26.09.2016. 


\title{
Resumo
}

Este artigo propõe um modelo de pontuação para a escolha de fundos de investimento em ações (FIAs) brasileiros de gestão ativa com alfa de Jensen positivo e significativo. Duas medidas de desempenho e oito características dos FIAs foram obtidas entre 2004 e 2014. O conjunto de características é amplo e foi codificado como variáveis binárias. A amostra conta com 1.417 fundos e minimiza o viés de sobrevivência porque inclui FIAs iniciados e encerrados. A pontuação foi estimada por regressão logística binária. Menos de dez por cento dos FIAs apresentaram alfa positivo e significativo. O modelo aponta o desempenho passado como a característica mais importante para selecionar um FIA com alfa significativamente positivo. A gestão independente, o investimento em cotas de outros FIAs e fundos iniciantes ou menos longevos também são importantes nessa seleção. Testes fora da amostra indicam que os FIAs de maior pontuação exibiram alfas significativamente positivos frequentemente e negativos raramente. Os FIAs de maior pontuação superam amiúde carteiras igualmente ponderadas, particularmente quanto ao retorno ajustado ao risco. Há várias indicações de que os gestores profissionais procuram limitar a volatilidade, mesmo que com o sacrifício do retorno. Há implicações relevantes para o investidor individual.

Palavras-chave: fundos de investimento em ações; avaliação de desempenho; carteiras igualmente ponderadas; investidor individual; Brasil.

\begin{abstract}
This article proposes a scoring model for the selection of actively managed Brazilian stock funds with positive and significant Jensen's alpha. Two performance measures and eight fund characteristics were obtained between 2004 and 2014. The characteristics set is broad and was coded as binary variables. The sample consists of 1,417 funds and minimizes survivorship bias because it includes new and discontinued funds. The scoring was estimated through a binary logistic regression. Less than ten percent of stock funds displayed significant positive alphas. The model denotes past performance as the most important characteristic to select a stock fund with a significant positive alpha. Independent management, investment in other FIA funds and new or younger funds also relate to this selection. Out of sample tests indicate that high scoring stock funds frequently exhibit significant positive and rarely significant negative alphas. High scoring stock funds frequently beat equally weighed portfolios, especially as to risk adjusted returns. There are several indications that professional managers seek to limit volatility, even if it means sacrificing returns. These are important implications for individual investors.
\end{abstract}

Key words: stock funds; performance evaluation; equally weighed portfolios; individual investor; Brazil. 


\section{Introdução}

Um investidor pode realizar seus investimentos diretamente ou buscar a gestão profissional em fundos de investimento. Estes fundos de investimento geridos por profissionais se beneficiam de custos de transação menores, oferecem maior liquidez, possibilitam o acesso a múltiplos mercados e podem até oferecer menor volatilidade do que investimentos análogos (Santiago \& Leal, 2015; Varga \& Wengert, 2011). Sanematsu (2013), por outro lado, argumenta que há problemas na gestão profissional, em especial os decorrentes de conflitos de interesse nos fundos de investimento em ações (FIAs) para investidores não qualificados. A Instrução 409 de 18 de agosto de 2004 da Comissão de Valores Mobiliários (CVM) define um FIA como aquele cujo risco provém principalmente da variação dos preços de ações e que deve ter pelo menos dois terços de seu capital composto por ações, outros títulos derivados de ações (tal como bônus de subscrição ou certificados de depósito de ações) ou cotas de outros fundos de ações. O FIA não está sujeito a limites de concentração por emissor, desde que seu regulamento contenha um alerta sobre tal concentração e os riscos que dela decorrem.

Este artigo oferece mais subsídios para a escolha, por parte de um investidor individual, entre um FIA ou uma carteira própria de ações. O principal objetivo foi oferecer uma técnica de pontuação dos FIAs de gestão ativa para identificar fundos com alfas positivos e significativos fora da amostra. A técnica emprega variáveis explicativas que podem ser facilmente obtidas e consideradas pelo investidor individual. Embora não se suponha que tal investidor saiba usar o modelo proposto, nem que este modelo espelha o processo decisório usado pelo investidor, espera-se que os resultados sugiram quais são as variáveis mais importantes, entre as empregadas, para se examinar na seleção de um FIA. Não se constatou o emprego deste tipo de modelo de pontuação no Brasil aplicado a FIAs, uma vez que o artigo nacional recente mais próximo examina um modelo de classificação, sem pretender uma pontuação, a partir de uma amostra bem menor do que a empregada neste estudo e potencialmente sujeita ao viés de sobrevivência (Oliviera \& Souza, 2015). Cuthbertson, Nitzsche e O'Sullivan (2016), por outro lado, reveem a literatura internacional sobre a associação entre o desempenho de fundos e suas características.

Este estudo também foi motivado pela mudança substancial no mercado brasileiro de fundos de ações e por outras características e lacunas na literatura nacional, tais como a presença de pequenas amostras de FIAs, o problema do viés de sobrevivência, a ausência da consideração simultânea de um conjunto mais amplo de características dos FIAs e a ausência de esforço de sintetizar as conclusões sugeridas pelo método empregado com foco no investidor individual menos sofisticado. Além disso, o mercado de FIAs cresceu $234 \%$ em quantidade de fundos e $111 \%$ no total de ativos sob gestão entre dezembro de 2004 (619 fundos e R \$ 95,2 bilhões) e dezembro de 2014 (2070 fundos e R \$ 201,0 bilhões), o último ano da amostra, em moeda constante de março de 2016 (Associação Brasileira das Entidades do Mercado Financeiro e de Capitais [Anbima], 2016). O crescimento substancial no número de FIAs se deu a partir de 2007, coincidindo com um bom momento de crescimento da economia brasileira e da bolsa nacional. Este artigo analisou o desempenho dos FIAs entre $1^{\circ}$ de setembro de 2004 e 31 de agosto de 2014 (10 anos), um período recente e com grande crescimento na atividade de gestão de FIAs, o que consiste em contribuição acessória.

A principal contribuição é averiguar se a técnica de pontuação dos FIAs de gestão ativa proposta facilita essa escolha ao discriminar os fundos com alfas de Jensen positivos e significativos no período fora da amostra de estimação. A pontuação foi apurada a partir de um conjunto amplo de características dos fundos facilmente obtidas por investidores individuais: natureza do gestor (independentes ou não), tipo de investidor a que se destina (qualificado ou não), tamanho, longevidade, uso de alavancagem, constituição segundo um fundo de investimento em cotas de fundos de investimento (FIC) e cobrança de taxa de performance. Além dessas características, considerou-se o desempenho passado segundo o Índice de Sharpe (IS) e o retorno. Todas as características foram codificadas como variáveis categóricas (e binárias) para que os coeficientes do modelo estivessem na mesma escala e pudessem ser somados para obtenção da pontuação. 
Outra contribuição é contrastar a rentabilidade de FIAs com as pontuações mais elevadas e a que poderia ser obtida diretamente pelo investidor individual por meio de carteiras igualmente ponderadas $(1 / \mathrm{N})$ com dez ações escolhidas pelo critério de melhor IS no quadrimestre anterior. Santiago e Leal (2015), entre outros, já apontaram que carteiras de ponderação igualitária com essas características são alternativas competitivas para investidores individuais em relação aos FIAs brasileiros. Nesta etapa, averiguou-se se os FIAs de melhor pontuação oferecem vantagens para um investidor individual que não emprega métodos complexos de otimização para formar sua carteira própria. $\mathrm{O}$ foco na escolha deste tipo de investidor individual é outra contribuição deste artigo.

Finalmente, mais uma contribuição pertinente é o tratamento do viés de sobrevivência ao se usar informações dos FIAs que estiveram ativos, isto é, que publicaram cotas junto à CVM, por pelo menos um subperíodo no período amostral total (entre $1^{\circ}$ de setembro de um ano da amostra e 31 de agosto do ano seguinte), e não apenas durante todo o período estudado. A amostra mais abrangente diminui o viés de sobrevivência, pois dos 3.342 FIAs que estiveram ativos em qualquer ponto do período amostral, somente 1.608 estavam ativos no seu final e apenas 242 se mantiveram ativos durante todo o tempo. A amostra empregada é, portanto, muito maior do que a de estudos precedentes que relacionaram o desempenho de FIAs com algumas de suas características e que contemplaram somente fundos sobreviventes, tal como Oliviera e Souza (2015) e Matos, Penna e Silva (2015).

Os resultados indicam que o modelo de pontuação proposto parece ter méritos para o investidor individual. Se usado pelo investidor, ele evita a seleção de FIAs com desempenho catastrófico (alfa negativo e significativo) e contribui para que se escolham FIAs com desempenho positivo excepcional na maioria dos períodos amostrais, pois os FIAs com melhor pontuação superam as carteiras de ponderação igualitária na maioria dos períodos de aplicação, particularmente quando o critério de desempenho é ajustado ao risco.

O desempenho dos anos mais recentes, medido pelo IS, parece ser a característica mais importante para se selecionar um FIA bem-sucedido, isto é, aquele cujo coeficiente significativo é o mais elevado, lembrando que todos os coeficientes estão na mesma escala, uma vez que todas as variáveis são categóricas binárias. O estudo indica que há persistência no desempenho dos gestores de sucesso, tal como apontaram Oliviera e Souza (2015). Os gestores de FIAs parecem se preocupar com a volatilidade, mesmo que com algum sacrifício de desempenho. Essa precaução dos gestores pode ser uma característica desejada por muitos investidores individuais e uma vantagem em relação às carteiras igualmente ponderadas. Por outro lado, cabe destacar que menos de dez por cento dos FIAs da amostra alcançaram alfas positivos e significativos, proporção muito próxima às relatadas por Castro e Minardi (2009) e que ainda pode incluir muitos gestores sortudos, como apontam Laes e Silva (2015). A seleção do FIA é, portanto, uma etapa crítica para o investidor.

Outras características contribuem positivamente para a seleção de FIAs com alfa positivo e significativo: a constituição como FIC, o direcionamento para investidores qualificados e o fato de ser um fundo iniciante ou pouco longevo. Por outro lado, o vínculo com grandes instituições financeiras, algumas delas com muitos clientes de varejo bancário, contribui negativamente, sendo um ponto favorável para gestores independentes. O tamanho do fundo e a taxa de performance não parecem influenciar no desempenho excepcional, talvez por serem dominados por outras características dos FIAs, como o direcionamento para investidores qualificados, a ausência de vínculo do gestor com uma grande instituição financeira e a longevidade.

O restante do trabalho consiste em uma revisão da literatura, seguida da seção que descreve a metodologia, destacando as fontes de dados, os critérios de classificação dos FIAs e os métodos empregados para a pontuação e avaliação de sua eficácia. A seção seguinte apresenta os resultados obtidos pelos FIAs segundo as características selecionadas, dá uma sugestão para a criação de um procedimento de pontuação para os FIAs e avalia seus resultados fora da amostra ao contrastar FIAs escolhidos com carteiras 1/N. A seção final reúne as conclusões, enumera algumas limitações e sugere temas para futuras investigações. 


\section{Antecedentes na Literatura}

\section{O alfa de FIAs no Brasil}

Entre os indicadores mais conhecidos de avaliação de desempenho de fundos de investimento estão o IS e o alfa de Jensen (Varga, 2001). A forma usual do IS é a apresentada no Apêndice, como uma razão entre o excesso de retorno e a volatilidade (desvio-padrão) do ativo. Israelsen (2005) afirma que o IS é problemático para ordenar ativos quando seu numerador é negativo. O IS, portanto, não foi a medida de avaliação empregada neste artigo, uma vez que os elevados valores das taxas de juros no Brasil o tornam negativo com muita frequência, invalidando o ordenamento de muitos FIAs. Oliviera e Souza (2015) enfrentaram este tipo de problema e atribuíram o valor zero para os ISs negativos, perdendo a capacidade de ordenar todos os FIAs de sua amostra. Indicadores de avaliação análogos ao IS, como a razão de informação, que é um IS generalizado (Sharpe, 1994), e a razão de Sortino (Sortino \& Price, 1994), não foram considerados pelo mesmo motivo.

O alfa de Jensen, por outro lado, não apresenta essa limitação quanto à ordenação quando é negativo. Varga (2001) apresenta a forma tradicional do alfa de Jensen como o intercepto resultante da estimativa de um modelo com um fator de risco sistemático que representa o Capital Asset Pricing Model (CAPM) na sua versão Sharpe-Lintner-Mossin. A Equação 1, que foi a forma implementada neste estudo, retrata essa forma tradicional do alfa. Um alfa positivo e significativo sugere que o gestor pode ter habilidade excepcional para aumentar a riqueza de seus clientes, além do que era esperado como resposta ao risco sistemático representado pelo(s) fator(es) de risco do modelo. Por outro lado, mesmo que o gestor apresente alfas positivos e significativos por vários períodos, isso ainda não elimina a possibilidade de pura sorte, particularmente quando a amostra de fundos é grande e bem maior do que o número de períodos em que o alfa é apurado (Laes \& Silva, 2015).

Uma forma alternativa de estimar o alfa pode ser a empregada por Carhart (1997), que aplicou um modelo de quatro fatores baseado no modelo de três fatores de Fama e French (1993) na análise de fundos estadunidenses. O primeiro fator representa o prêmio de risco da carteira de mercado, que é o único fator de risco sistemático da versão Sharpe-Lintner-Mossin do CAPM. Ele é escoltado por dois fatores adicionais: a diferença entre os retornos de carteiras diversificadas de ações de empresas pequenas e grandes (small minus big, ou SMB); e a diferença entre os retornos de carteiras diversificadas de ações de índice book-to-market alto e baixo (high minus low, ou HML). Carhart (1997) examinou fundos de ações dos EUA e introduziu a diferença entre os retornos de carteiras diversificadas de ações de empresas que lograram retornos maiores em período recente e as com retornos menores no mesmo período (winners minus loosers, ou WML) como fator adicional.

Argolo, Leal e Almeida (2012) argumentam que o modelo de Fama e French (1993) tem algum sucesso na explicação de retornos históricos de ações brasileiras dentro da amostra (in sample), mas que não é confiável para a previsão dos retornos. A dificuldade reside em se estimar os valores esperados de SMB e HML no Brasil para previsões fora da amostra porque as médias históricas desses fatores não exibiram valores que levassem a estimativas razoáveis do custo do capital próprio das empresas. Além disso, os coeficientes desses fatores também não apresentaram estabilidade nos subperíodos analisados. Os autores afirmam ainda que o beta do prêmio de risco de mercado foi o único coeficiente que apresentou significância em todos os subperíodos, com mais estabilidade. Tais autores concluem, portanto, que estimativas mais razoáveis do custo de capital próprio seriam obtidas somente com o CAPM, com a vantagem da menor complexidade.

Castro e Minardi (2009) analisaram os retornos líquidos de 577 FIAs de gestão ativa entre janeiro de 1996 e outubro de 2006. Eles estimaram o alfa segundo um modelo de cinco fatores: os quatro de Carhart (1997) e mais um representando a sincronia com o mercado (market timing). A proporção de coeficientes dos fatores adicionais ao do CAPM com significância a 5\% foi pequena: 14,9\% para SMB; $10,2 \%$ para HML e 10,9\% para WML. Essa evidência corrobora e reforça as conclusões de Argolo et al. (2012), pois se referem a carteiras bem diversificadas de ações (os FIAs) e são in sample, que são 
situações nas quais esses modelos apresentam melhor aderência. A versão de Sharpe-Lintner-Mossin do CAPM bastaria para a maioria dos FIAs. Os resultados desses dois artigos justificam a escolha pelo alfa tradicional de Jensen, estimado por um modelo de um fator que representa o CAPM, para aquilatar o desempenho de fundos brasileiros.

Castro e Minardi (2009) não rejeitam a hipótese de que o desempenho dos FIAs de gestão ativa seja igual ao dos de gestão passiva. Eles ainda afirmam que, na média, não houve evidência de alfa positivo. O alfa médio da amostra de FIAs ativos é ligeiramente negativo (13 pontos base). Os autores encontram 5\% dos FIAs ativos com alfa positivo e significativo e 11,3\% com alfa negativo e significativo. Matos e Rocha (2009) ajustam modelos de Fama e French (1993) e Carhart (1997) para FIAs e também concluem que os coeficientes dos fatores adicionais ao do CAPM não apresentam a significância desejada. Eles sugerem, ainda, que estudos futuros poderiam empregar modelos lineares com fatores particulares aos FIAs, o que é consistente com a proposta deste artigo. Laes e Silva (2015) afirmam que a maior parte da literatura internacional não detecta desempenho excepcionalmente superior para fundos de ações. Eles empregaram técnicas de simulação, derivadas das propostas por Fama e French (2010), para analisar se os alfas positivos e significativos se deviam à sorte ou à habilidade e concluíram que apenas 19 dos 1.111 FIAs que analisaram $(1,7 \%)$ apresentaram desempenho excepcional; também alegam que mais da metade dos FIAs apresentou alfa negativo.

Esta seção pode ser resumida pela constatação de que são poucos os FIAs de gestão ativa que alcançam alfas positivos e significativos e que, mesmo assim, a maioria deles provavelmente contou com a sorte para lograr esse resultado. Outra conclusão relevante para este artigo é que os coeficientes dos fatores adicionais ao prêmio de risco de mercado (CAPM) do modelo de Carhart (1997) não atingem significância estatística na grande maioria dos casos, pouco contribuindo para a explicação dos retornos, mesmo em exercícios dentro da amostra. Finalmente, cabe notar que alguns dos autores revistos sugerem que características específicas dos FIAs brasileiros poderiam ser consideradas nos modelos de previsão de desempenho. Esses aspectos nortearam as escolhas metodológicas deste artigo.

\section{Características dos FIAs e desempenho}

Cuthbertson et al. (2016) afirmam que os desempenhos dos fundos podem ser influenciados por suas características, tais como o desempenho passado, idade do fundo, taxas de performance, entre outros aspectos. Matos et al. (2015) examinam 68 FIAs de gestão ativa brasileiros entre janeiro de 1998 e junho de 2007 e concluem que os FIAs de melhor desempenho cobram taxa de performance, aplicam taxas de administração mais baixas, são menos longevos, estão associados a instituições financeiras de controle privado e buscam o desempenho ajustado ao risco. Eles recomendam o uso de técnicas empíricas que não sejam limitadas pela necessidade de fundos que permaneceram ativos durante todo o período amostral. Tal recomendação também contribuiu para a escolha metodológica do presente artigo.

Cuthbertson et al. (2016) relatam que há persistência de desempenho passado para fundos mútuos na literatura internacional, particularmente para os fundos perdedores, enquanto que Jagannathan, Malakhov e Novikov (2010) alegam que os hedge funds apresentam persistência particularmente entre os fundos vencedores. Oliviera e Sousa (2015) investigam qual é a probabilidade de um FIA manter o bom desempenho passado no Brasil. Eles partiram de 173 FIAs brasileiros sobreviventes entre janeiro de 2003 e dezembro de 2010. Os autores usaram os anos de 2003 a 2006 para classificar os FIAs em quartis segundo o IS. A variável dependente de seu modelo classificatório assumiu o valor 1 para os 42 FIAs no quartil com os maiores ISs e 0 para os 42 FIAs no quartil com ISs menores. Os autores estimaram a probabilidade de bom desempenho com dados dos FIAs entre 2007 e 2010 por meio de regressão logística binária sem constante. As variáveis explicativas contemplam indicadores de avaliação de desempenho bem conhecidos além de características dos FIAs, tais como: o valor da taxa de administração; a cobrança de taxa de performance e a autorização para alavancagem, essas duas como variáveis binárias. $\mathrm{O}$ modelo classificatório final dos autores reteve as seguintes variáveis, listadas segundo sua importância (com o sinal de seu coeficiente entre parênteses): o valor da taxa de administração (negativo), razão de Treynor (positivo), IS generalizado (positivo), índice de Modigliani e Modigliani (M2) (positivo) e a binária para a taxa de performance (positivo). Os autores alegam obter 
$81 \%$ de acerto na classificação dos 84 FIAs como membros dos quartis superior e inferior de desempenho.

Milani e Ceretta (2012) procuraram identificar fundos de melhor desempenho segundo seu tamanho e longevidade. Eles examinaram 139 FIAs de gestão ativa e passiva entre abril de 2001 e abril de 2009. Os autores usaram FIAs que reportaram cotas em pelo menos metade do período. Seus resultados para os FIAs ativos indicam que a idade influencia negativamente o retorno, enquanto o PL não apresentou efeito. Finalmente, Cuthbertson et al. (2016) afirmam que encontrar fundos bemsucedidos ex-ante é muito difícil, e Chen, Lai e Wu (2016) afirmam que gestores profissionais de esquemas de pensão estadunidenses tendem a escolher fundos vencedores para constar entre as opções disponíveis para os beneficiários, mas que esta persistência dura pouco e que este cardápio de fundos não tem poder preditivo sobre o sucesso destes fundos no médio e longo prazo.

\section{Metodologia}

\section{Período e seleção da amostra de FIAs}

A amostra inicial continha 2.498 FIAs que estiveram em funcionamento durante qualquer momento do período de estudo (1/9/2004 a 29/8/2014). O final do período foi determinado pela época de coleta dos dados. O início do período foi arbitrado pela escolha de se empregar um horizonte de 10 anos. Considerou-se somente FIAs de gestão ativa (não indexados), ou seja, os que possuíam classificação Ações na CVM, Ações - Ativo na base de dados Quantum Axis® e classificação ANBIMA diferente de Ibovespa Indexado ou de IBrX Indexado, que foram os filtros empregados na consulta feita na base de dados Quantum Axis ${ }^{\circledR}$ no dia 5/7/2014.

A consulta foi realizada na sede da empresa que produz o banco de dados Quantum Axis ${ }^{\circledR}$ para possibilitar a inclusão dos FIAs liquidados, que não estão disponíveis no sistema Quantum Axis Online, que é a interface acessada por seus clientes. Os FIAs que não divulgaram cotas por pelo menos um período completo ( $1^{\circ}$ de setembro de um ano a 31 de agosto do ano subsequente) foram eliminados da amostra, analogamente a Laes e Silva (2015). Este critério foi empregado porque muitas das características dos fundos usadas no modelo de pontuação não estão disponíveis no banco de dados consultado e os fundos não poderiam ser incluídos no modelo de pontuação. Sanematsu (2014), contudo, considera o viés de sobrevivência e conclui que ele não altera seus resultados principais e a representatividade de sua amostra de FIAs.

Os fundos master também foram eliminados, pois além de suas cotas serem compradas pelos respectivos feeders, eles geralmente não cobram taxa de administração e, portanto, a sua permanência na amostra incluiria taxas de retorno diferentes das que seriam obtidas por investidores individuais. Este critério não deve afetar a representatividade da amostra, uma vez que boa parte dos ativos dos fundos master estão refletidos nos ativos dos fundos feeder correspondentes.

Finalmente, os FIAs considerados muito pequenos, cujo patrimônio líquido nunca é superior a R\$ 5 milhões, que é um filtro um pouco maior do que o empregado por Laes e Silva (2015) e Castro e Minardi (2009), inativos ou com problemas na série histórica de cotas na base de dados Quantum Axis® também foram excluídos. Os FIAs muito pequenos também não devem afetar a representatividade, justamente pelo pequeno tamanho, o que é sustentado pela evidência de Sanematsu (2014) e Castro e Minardi (2009), embora estes autores indiquem que os fundos menores apresentam maior frequência de alfas negativos. $\mathrm{O}$ valor de $\mathrm{R} \$ 5$ milhões é intermediário entre os valores de corte empregados por Castro e Minardi (2009) (R \$ 1,5 milhão) e Sanematsu (2014) (R \$ 10 milhões). A amostra final contou com 1.417 FIAs. Os critérios de inclusão de FIAs que iniciaram ou encerraram suas atividades durante todo o período amostral são análogos aos empregados por Castro e Minardi (2009) e Laes e Silva (2015). 
Os retornos diários líquidos de cada FIA foram calculados com os valores diários de suas cotas na base de dados Quantum Axis ${ }^{\circledR}$. O retorno é dito líquido no contexto deste estudo porque o valor das cotas é deduzido da taxa de administração, usualmente cobrada como um percentual do patrimônio líquido investido, e de performance, que pode ser cobrada quando o gestor atinge retorno superior a um indicador em um período pré-determinado. A taxa de performance pode ser considerada uma forma de remuneração pelo bom desempenho do gestor e uma forma de alinhamento de seus interesses com os dos cotistas. Os valores das cotas também são deduzidos de despesas operacionais do fundo. $\mathrm{O}$ investidor de um FIA pode incorrer em outros custos, tal como taxas de entrada ou saída, que não são usuais no Brasil e que não são consideradas nos valores das cotas (Varga \& Wengert, 2011). Estas últimas taxas foram ignoradas, o que equivale a supor que o investidor individual não incorre em custos de entrada e não retira seu investimento durante o período de carência.

\section{Classificação e avaliação do desempenho dos FIAs}

Os FIAs foram classificados segundo dez características definidas em detalhes no Apêndice. Todas as características selecionadas são de fácil obtenção ou observação pelo investidor individual. Contudo, não se presume que o investidor individual vá executar o modelo aqui proposto nem que o modelo reproduz o processo decisório do investidor individual. Isto é, embora as variáveis empregadas estejam disponíveis e sejam de fácil compreensão pelo investidor individual, seu modo mental de decisão não pode ser replicado pelo modelo proposto. Pode ser, ainda, que o investidor empregue outras variáveis que não estão disponíveis no banco de dados consultado, tais como seu relacionamento pessoal ou comercial com o gestor ou a instituição gestora, ou a exposição na mídia do gestor de um FIA. Sendo assim, o modelo visa somente verificar que características ao alcance do investidor individual, disponíveis no banco de dados consultado, poderiam ser as mais importantes a serem consideradas, mas não se pode supor que esse investidor vá usar ou executar o modelo proposto ou que o modelo possa reproduzir seu processo decisório. O período total de 120 meses foi dividido em dez subperíodos com a duração de 12 meses cada um, iniciados no primeiro dia útil de setembro de um ano e encerrados no último dia útil de agosto do ano seguinte. Doravante, pode-se usar a palavra ano para denotar estes períodos de 12 meses que constituem os anos amostrais.

A discussão sobre indicadores de desempenho na revisão de literatura levou à opção pela forma original do alfa de Jensen, que foram estimados para cada um dos 1.417 FIAs da amostra em cada um dos anos amostrais em que apresentou retornos diários, resultando em um alfa por ano amostral para cada FIA. A Equação 1 retrata a regressão linear estimada pelo método dos mínimos quadrados ordinários. As estimativas foram corrigidas pelo procedimento de Newey-West, uma vez que o teste de White rejeitou a hipótese de homocedasticidade em $99,1 \%$ das regressões ao nível de 5\% de significância, e o teste de Ljung-Box rejeitou a hipótese de ausência de autocorrelação dos erros em 47\% das regressões realizadas, também ao nível de $5 \%$ de significância. O intercepto da regressão retratada pela Equação 1 é a estimativa do alfa de Jensen para o FIA $j\left(\alpha_{j}\right)$, o coeficiente angular é o beta do FIA $j\left(\beta_{j}\right)$, e o termo $\varepsilon_{j, t}$ é o erro, cujo valor esperado é nulo.

$$
R_{j, t}-R_{f, t}=\alpha_{j}+\beta_{j}\left(R_{m, t}-R_{f, t}\right)+\varepsilon_{j, t}
$$

$R_{j, t}$ é o retorno diário líquido de cada FIA $j$ calculado a partir da variação percentual das cotas do fundo obtidas conforme procedimento já descrito. A taxa livre de riscos $\left(R_{f, t}\right)$ foi representada pelo valor diário do rendimento do CDI porque se espera que o investidor de um FIA tenha acesso a investimentos atrelados a essa taxa, configurando seu custo de oportunidade de baixíssimo risco. Além disso, Carneiro e Leal (2015), Sanematsu (2014) e Varga (2001), por exemplo, usam esta taxa como a livre de risco e afirmam que esta taxa é o benchmark mais comum no mercado e na lâmina dos fundos, o que também asseveram Oliviera e Souza (2015) e Matos, Linhares e Sylvestre (2012).

Os retornos diários do Ibovespa $\left(R_{m, t}\right)$ foram empregados para representar o mercado acionário brasileiro, já que as ações que o constituem representam $85 \%$ do número e do volume de negociações de ações na bolsa (BM\&FBOVESPA, 2015). A diferença entre $R_{m, t}$ e $R_{f, t}$ pode assumir o valor efetivamente observado, negativo ou positivo, não havendo ajustes quando negativo. As séries de 
retorno diárias do CDI e Ibovespa foram obtidas na base de dados Quantum Axis ${ }^{\circledR}$. Especificamente, empregou-se a série Ibovespa MtM (Mark to Market ou Marcação a Mercado), que é a união dos retornos do Ibovespa médio até 2 de maio de 2008 e de fechamento, a partir desta data, aderente à mudança na metodologia de marcação a mercado dos ativos dos FIAs introduzida pela Instrução CVM 465 de 20/2/2008.

\section{Geração e validação do modelo de pontuação}

A Equação 2 retrata a regressão logit, que verifica se um modelo de pontuação dos FIAs, com base em características acessíveis ao investidor individual, é capaz de ajudar na escolha dos FIAs com mais chances de gerar alfa de Jensen positivos e significativos para os cotistas. Novamente, destaca-se que não se presume que o investidor individual usará ou executará tal modelo nem que ele reproduz o processo decisório do investidor individual. Ele serve apenas para que se identifique que variáveis, entre aquelas elencadas como acessíveis a esse investidor e disponíveis no banco de dados consultado, ele deveria usar para selecionar fundos. A estimativa empregou matrizes de covariâncias robustas de HuberWhite, cuja escolha, em vez da correção de Newey-West, ocorreu porque o software Eviews ${ }^{\circledR}$ usado para regressões logit não oferece esta alternativa. Cada ano amostral em que se estimou o modelo para cada fundo $j$ é denotado por $t$. $\ln \left(\frac{p_{j, t}}{1-p_{j, t}}\right)$; é o logaritmo natural da chance (odds, em inglês). As demais variáveis estão relacionadas e definidas no Apêndice.

Todas as variáveis explicativas são binárias e assumem os valores 0 ou 1 . O uso de variáveis categóricas binárias, mesmo que para variáveis originalmente não-categóricas, foi necessário para que se pudesse obter uma pontuação resultante da soma de coeficientes que estivessem na mesma escala. É por isso que as variáveis Idade, PL, Novo, Ret e Sharpe foram estimadas na forma binária em função de informações do ano anterior, como definido no Apêndice. Além disso, esta forma de codificação permite que se avaliem as variáveis explicativas mais importantes diretamente pelos seus coeficientes, em contraste com o procedimento de Oliviera e Souza (2015). Por isso, a taxa de administração não foi incluída entre as características dos FIAs examinadas porque todos os FIAs da amostra cobram taxa de administração e seu efeito já estaria considerado nos retornos líquidos. Por outro lado, optou-se pela inclusão de uma variável para a existência da taxa de performance porque ela é opcional e pode indicar o alinhamento de interesses entre os gestores dos FIAs e seus clientes (Varga \& Wengert, 2011).

$$
\begin{aligned}
& \operatorname{logit}\left(p_{j, t}\right)=\ln \left(\frac{p_{j, t}}{1-p_{j, t}}\right)=\beta_{0, t}+\beta_{1, t} B C_{j, t}+\beta_{2, t} P_{j, t}+\beta_{3, t} \text { Idade }_{j, t}+\beta_{4, t} \text { Alav }_{j, t}+ \\
& \beta_{5, t} I Q_{j, t}+\beta_{6, t} \text { FIC }_{j, t}+\beta_{7, t} \operatorname{Perf}_{j, t}+\beta_{8, t} \text { Ret }_{j, t}+\beta_{9, t} \text { Sharpe }_{j, t}+\beta_{10, t} \text { Novo }_{j, t}
\end{aligned}
$$

A variável dependente que representa empiricamente o logaritmo natural da chance é binária e gerada por $p_{j, t}$, que assume o valor 1 caso o FIA tenha gerado alfa de Jensen significativo ao nível de $5 \%$ no ano amostral, ou zero no caso contrário, podendo o alfa ser positivo ou negativo. $\mathrm{O}$ vetor de coeficientes $\beta_{1, t}$ a $\beta_{10, t}$ se indexa a cada ano. Os regressores foram definidos no Apêndice. As variáveis categóricas binárias indicam, quando assumem o valor 1 , que o fundo está associado a uma grande instituição financeira ou banco comercial (BC), permite alavancagem (Alav), destina-se a investidores qualificados (IQ), investe em cotas de outros fundos (FIC), cobra taxa de performance (Perf) e é seu primeiro ano completo de operação (Novo). As demais variáveis categóricas binárias na Equação 2 indicam que o patrimônio líquido do fundo (PL), sua idade (Idade), retorno (Ret) e Índice de Sharpe (Sharpe) no período anterior estão acima da mediana da amostra.

O primeiro ano da amostra, entre setembro de 2004 e agosto de 2005, foi usado somente para estimar as variáveis que são função da mediana da amostra ou de informações do ano anterior (Idade, PL, Novo, Ret e Sharpe) no ano seguinte (setembro de 2005 a agosto de 2006), que foi, de fato, o primeiro ano para estimação. Sendo assim, entre os nove anos disponíveis para estimar, optou-se por usar quatro para estimar os parâmetros para uso fora da amostra no ano subsequente, resultando em cinco anos de aplicação fora da amostra (os cinco anos mais recentes). Entendeu-se que três anos (ou menos) seriam muito pouco para estimar os parâmetros (gerando erros-padrão excessivos), e quatro, o 
suficiente, pois assim ficamos com cinco anos de projeções fora da amostra, um número razoável para que o modelo pudesse ser testado, considerando-se o período amostral de dez anos. Cada ano amostral em que cada um dos 1.417 FIAs da amostra divulgou cotas do início ao fim do período representa uma observação do alfa de Jensen. Estimou-se a Equação 2 com as 6.371 observações obtidas $\left(\alpha_{j}\right)$.

Os modelos de cada período de aplicação foram estimados considerando os quatro anos amostrais anteriores agregados, isto é, como um pooled model. A Equação 2 representa tal modelo e, portanto, para cada ano de aplicação foi gerado um conjunto de coeficientes válidos para todos os FIAs analisados. Houve, então, um total de cinco períodos de aplicação, sendo que o primeiro foi entre setembro de 2009 e agosto de 2010, e o último, entre setembro de 2013 e agosto de 2014. O modelo foi, em consequência, estimado fora da amostra. A escolha de 4 anos amostrais se baseou no tamanho total da amostra (10 anos), na necessidade de testes fora da amostra e na estabilidade dos betas encontrados. A pontuação de cada FIA é o logaritmo natural da chance estimada em cada período de aplicação do modelo. A metodologia de escolha também procurou refletir variáveis que possam ser consideradas no processo decisório de um investidor individual, que olha para características de períodos anteriores para selecionar fundos de investimentos sem, contudo, presumir que ele use qualquer tipo de estatística ou modelo.

Os FIAs com as maiores pontuações em cada um dos modelos (nos respectivos períodos de aplicação) foram comparados a carteiras $1 / \mathrm{N}$ em testes fora da amostra quanto ao retorno líquido e IS. As carteiras 1/N continham 10 ações selecionadas pelo critério de maior IS no quadrimestre anterior e foram rebalanceadas quadrimestralmente, tal como proposto por Carneiro e Leal (2015). O investimento inicial considerado para o cálculo dos custos de transação da carteira $1 / \mathrm{N}$ foi de $\mathrm{R} \$ 300.000,00$, e os custos de transação foram estimados de acordo com a metodologia de Carneiro e Leal (2015), na qual cada ordem tem um custo fixo de $\mathrm{R} \$ 15,00$ e taxa de emolumentos e liquidação de $0,0325 \%$, cobrada pela Bolsa de Valores, Mercadorias e Futuros (BM\&FBovespa) e pela Companhia Brasileira de Liquidação e Custódia (CBLC), além do Imposto de Renda (IR) de 15\% incidente sobre o ganho de capital nos meses em que há vendas em um montante superior a $\mathrm{R} \$ 20.000,00$. O montante de $\mathrm{R} \$$ $300.000,00$ foi o maior analisado por Carneiro e Leal (2015) e o que menos sofria redução do retorno bruto (apenas 0,44\% acumulados ao longo de 10 anos) devido a custos de transação. Como ele ainda é um valor factível para um investidor individual, resolveu-se adotá-lo como base, uma vez que os retornos dos FIAs também são líquidos de vários custos de transação, mas não do IR sobre ganho de capital. Entendeu-se que essa escolha poderia colocar as duas alternativas de forma mais equitativa para a comparação porque, como as comparações foram feitas para cada ano da amostra, a suposição é que o investidor individual permanece investido a cada ano nos FIAs examinados, não resgatando e não pagando, portanto, o IR, enquanto que, no caso das carteiras $1 / \mathrm{N}$, há rebalanceamento quadrimestral (por construção) e, portanto, incidência intermediária de IR (nos dois rebalanceamentos intra-anuais). Ressalta-se, assim, que as rentabilidades comparadas serão as rentabilidades antes do pagamento de IR ao final de cada ano em questão, tornando a comparação equitativa.

\section{Resultados}

\section{Análise univariada preliminar}

A Tabela 1 oferece as diferenças do retorno médio e das variâncias dos FIAs e sua significância segundo cada variável binária definida no Apêndice. Estatísticas descritivas mais detalhadas foram omitidas por falta de espaço, mas estão disponíveis com os autores. O quadro que emerge dessa análise preliminar é que FIAs iniciantes ou menos longevos, com gestão independente, voltados para investidores qualificados, que cobram taxa de performance e com bom desempenho no ano anterior podem apresentar maior probabilidade de se situar entre aqueles de maior retorno no ano seguinte. FIAs maiores e mais longevos, vinculados a grandes instituições financeiras, que podem empregar alavancagem e com desempenho melhor no ano anterior, tenderam a exibir variância menor no ano seguinte. A constatação de persistência de desempenho na análise univariada é consistente com os 
resultados de Oliviera e Souza (2015). A importância da taxa de performance também corresponde à evidência de Matos et al. (2015) e Oliviera e Souza (2015). A pouca longevidade foi uma característica apontada como relevante por Matos et al. (2015). O comportamento inconclusivo do PL do FIA já fora sugerido por Milani e Ceretta (2012).

Tabela 1

Diferenças de Médias e Variâncias dos Retornos dos FIAs Segundo Categorias Selecionadas

\begin{tabular}{|c|c|c|c|c|c|c|c|c|c|c|c|}
\hline Período & Alav & $\mathrm{BC}$ & FIC & Idade & IQ & Novo & Perf & PL & Ret & Sharpe & $\mathrm{N}^{\mathrm{o}}$ Sig. \\
\hline \multicolumn{12}{|c|}{ Painel A: diferenças das médias dos retornos anuais } \\
\hline 2004-05 & $-5,16^{*}$ & $8,14^{*}$ & $-7,09 *$ & ND & $-3,44$ & ND & $-6,03 *$ & ND & ND & ND & 4 \\
\hline 2005-06 & 3,09 & $-1,36$ & 2,96 & $-1,82$ & 1,80 & 3,50 & $4,82^{*}$ & $-1,44$ & 1,63 & 2,73 & 1 \\
\hline 2006-07 & $-3,52$ & $-4,79$ & $-2,00$ & $-9,30^{*}$ & 0,40 & 0,89 & 5,21 & $-2,89$ & 0,17 & $-0,33$ & 1 \\
\hline 2007-08 & 1,04 & $-1,62$ & $-3,07 *$ & $3,77^{*}$ & 1,95 & $-2,93^{*}$ & $-2,20$ & 0,53 & $-3,17^{*}$ & $-2,79 *$ & 5 \\
\hline 2008-09 & $5,45^{*}$ & $-4,77^{*}$ & $4,93^{*}$ & $-4,62 *$ & $3,33^{*}$ & $3,09^{*}$ & $6,04 *$ & $-3,52 *$ & $-1,35$ & $-1,43$ & 8 \\
\hline 2009-10 & $2,57^{*}$ & $-4,70^{*}$ & $4,68 *$ & $-5,52 *$ & $4,96^{*}$ & 2,97 & $8,72^{*}$ & $-1,36$ & $6,45^{*}$ & $6,58^{*}$ & 8 \\
\hline 2010-11 & 1,10 & $-3,76^{*}$ & $1,95^{*}$ & $-10,92 *$ & $4,44 *$ & $4,58^{*}$ & $2,74 *$ & $-1,04$ & $5,82 *$ & $6,71^{*}$ & 8 \\
\hline 2011-12 & $2,92 *$ & $-2,61 *$ & $3,47^{*}$ & $-4,62 *$ & $6,03 *$ & $4,29^{*}$ & $2,49^{*}$ & $-0,08$ & $9,24 *$ & $9,35^{*}$ & 9 \\
\hline $2012-13$ & $3,14^{*}$ & $-4,44^{*}$ & $4,63^{*}$ & $-3,20^{*}$ & $5,05^{*}$ & $2,96^{*}$ & $3,49^{*}$ & $1,61^{*}$ & $6,49^{*}$ & $6,81^{*}$ & 10 \\
\hline 2013-14 & $-0,92$ & $5,01 *$ & 1,21 & $-0,19$ & $-1,52$ & 1,86 & $-3,50 *$ & 0,54 & $-2,14^{*}$ & $-2,36^{*}$ & 4 \\
\hline $\mathrm{N}^{\mathrm{o}}$ sig. & 5 & 7 & 7 & 7 & 5 & 5 & 8 & 2 & 6 & 6 & - \\
\hline \multicolumn{12}{|c|}{ Painel B: razão de variâncias das taxas de retorno } \\
\hline $2004-05$ & $0,35^{*}$ & $1,34^{*}$ & $0,27 *$ & ND & $0,69^{*}$ & ND & $0,55^{*}$ & ND & ND & ND & 5 \\
\hline 2005-06 & 0,82 & $0,59^{*}$ & $0,46^{*}$ & 0,81 & 1,02 & $1,86^{*}$ & $1,57^{*}$ & $0,66^{*}$ & $0,68 *$ & 0,82 & 6 \\
\hline 2006-07 & $0,39 *$ & $0,55^{*}$ & $0,41^{*}$ & $0,26^{*}$ & $1,72^{*}$ & $0,60^{*}$ & $2,04 *$ & $0,58 *$ & $0,28 *$ & $0,36^{*}$ & 10 \\
\hline 2007-08 & $0,81^{*}$ & $0,76^{*}$ & $0,43^{*}$ & 1,10 & 1,12 & $1,36^{*}$ & $0,81^{*}$ & 0,96 & $0,52 *$ & $0,54 *$ & 7 \\
\hline 2008-09 & $1,70^{*}$ & $0,37^{*}$ & 0,93 & $0,57^{*}$ & $1,36^{*}$ & $1,35^{*}$ & $1,27^{*}$ & $0,63 *$ & 1,16 & 1,12 & 7 \\
\hline 2009-10 & $0,70^{*}$ & $0,61^{*}$ & 0,88 & $0,67^{*}$ & $1,37^{*}$ & $1,66^{*}$ & $1,34^{*}$ & $0,72 *$ & $0,78^{*}$ & $0,78^{*}$ & 9 \\
\hline 2010-11 & 0,98 & $0,71^{*}$ & $0,78^{*}$ & $0,83^{*}$ & $1,40^{*}$ & 0,92 & 1,09 & 0,99 & 0,88 & 0,99 & 4 \\
\hline 2011-12 & 0,96 & $0,82^{*}$ & $0,61^{*}$ & 0,86 & 1,09 & $0,73^{*}$ & 0,99 & $0,84^{*}$ & 1,06 & 1,06 & 4 \\
\hline 2012-13 & 1,02 & $0,65^{*}$ & $0,61 *$ & $0,68^{*}$ & $1,35^{*}$ & 1,14 & 0,99 & 0,97 & $0,65^{*}$ & $0,61 *$ & 6 \\
\hline 2013-14 & $0,61^{*}$ & 1,02 & $0,39 *$ & 1,05 & $0,52 *$ & 0,92 & $0,61 *$ & 1,06 & 0,85 & $0,81 *$ & 5 \\
\hline $\mathrm{N}^{\mathrm{o}}$ sig. & 6 & 9 & 8 & 5 & 7 & 6 & 7 & 5 & 5 & 5 & - \\
\hline
\end{tabular}

Nota. Diferença entre a média dos retornos dos FIAs quando a variável binária é igual a 1, e quando é igual a 0 no Painel A. A hipótese nula é de que tal diferença é zero, ou seja, que as médias sejam iguais. Razão entre a variância dos retornos dos FIAs quando a variável categórica é igual a 1 sobre a variância quando ela é igual a 0 no Painel B. A hipótese nula aqui é de que tal razão é um, ou seja, que as variâncias sejam iguais. As variáveis categóricas estão definidas em detalhe no Apêndice. As variáveis categóricas binárias indicam, quando assumem o valor 1, que o fundo está associado a uma instituição financeira de grande porte ou banco comercial (BC), permite alavancagem (Alav), destina-se a investidores qualificados (IQ), investe em cotas de outros fundos (FIC), cobra taxa de performance (Perf) e é seu primeiro ano completo de operação (Novo). As demais variáveis categóricas binárias indicam que o patrimônio líquido do fundo (PL), sua idade (Idade), retorno (Ret) e Índice de Sharpe (Sharpe) no período anterior estavam acima da mediana da amostra.

* indica, no Painel A, a significância a 5\% do teste t calculado segundo Welch: $t=\frac{\bar{x}_{1}-\bar{x}_{2}}{\sqrt{\frac{s_{x 1}^{2}}{n_{1}}+\frac{s_{x 2}^{2}}{n_{2}}}}$, no qual a diferença das médias em cada categoria da variável está no numerador, $s^{2}$ são as variâncias das variáveis em cada categoria e $n$ é o número de observações da variável em cada categoria. No Painel B, mostra-se a significância a $5 \%$ do teste $F$ unicaudal, calculado dividindo-se a variância maior pela menor. 
Por outro lado, esta análise preliminar indica a importância da autorização para uso de alavancagem, enquanto Oliviera e Souza (2015) não relacionam esta variável como determinante em seu modelo. Finalmente, cabe destacar que estes autores não examinaram as variáveis que indicam vínculo com grandes instituições financeiras, direcionamento para investidores qualificados, constituição segundo um FIC e início recente de atividades do FIA, apontadas por outros autores como importantes para a determinação da performance, em especial Sanematsu $(2013,2014)$, que indica que o início de atividade do FIA e sua orientação para investidores de varejo são importantes na determinação do desempenho e de possíveis conflitos de interesse que afetam o retorno final para o investidor. Essas variáveis foram incluídas para abarcar esses aspectos.

\section{Alfa de Jensen}

A evidência na Tabela 2 sugere que, em menos de dez por cento das oportunidades, os FIAs brasileiros foram capazes de gerar alfas positivos e significativos ao nível de cinco por cento nos dez anos amostrais. Esta evidência é consistente com a apresentada por Castro e Minardi (2009). De forma geral, a proporção de alfas positivos e significativos é maior do que a de negativos e significativos, mas o percentual de alfas positivos e significativos variou muito entre os anos amostrais. Os anos amostrais com menor quantidade de alfas positivos e significativos são os com maior quantidade de alfas negativos e significativos (2007-08 e 2013-14). Esses períodos correspondem à crise financeira internacional e a um ano difícil para a economia brasileira, em que a política econômica começou a dar sinais claros de esgotamento e o produto interno bruto cresceu pouco ou nada. Ainda assim, o Ibovespa exibiu bom desempenho em 2013-14.

Tabela 2

Quantidade e Proporção de Alfas de Jensen Significativos por Ano Amostral

\begin{tabular}{cccccccccccc}
\hline Período & $\begin{array}{c}\text { Total de } \\
\text { Fundos }\end{array}$ & $\begin{array}{c}\text { Retorno do } \\
\text { Ibovespa }\end{array}$ & CDI & Alfa $>0(10 \%)$ & Alfa $>0(5 \%)$ & Alfa $<0(10 \%)$ & Alfa $<0(5 \%)$ \\
\hline $2004-05$ & 221 & $22,98 \%$ & $18,25 \%$ & 35 & $15,84 \%$ & 20 & $9,05 \%$ & 13 & $5,88 \%$ & 9 & $4,07 \%$ \\
$2005-06$ & 261 & $29,20 \%$ & $16,80 \%$ & 46 & $17,62 \%$ & 22 & $8,43 \%$ & 14 & $5,36 \%$ & 8 & $3,07 \%$ \\
$2006-07$ & 319 & $50,80 \%$ & $12,59 \%$ & 82 & $25,71 \%$ & 59 & $18,50 \%$ & 6 & $1,88 \%$ & 6 & $1,88 \%$ \\
$2007-08$ & 472 & $1,91 \%$ & $11,30 \%$ & 6 & $1,27 \%$ & 4 & $0,85 \%$ & 144 & $30,51 \%$ & 103 & $21,82 \%$ \\
$2008-09$ & 646 & $1,45 \%$ & $11,61 \%$ & 20 & $3,10 \%$ & 10 & $1,55 \%$ & 44 & $6,81 \%$ & 30 & $4,64 \%$ \\
$2009-10$ & 738 & $15,32 \%$ & $9,04 \%$ & 169 & $22,90 \%$ & 129 & $17,48 \%$ & 78 & $10,57 \%$ & 42 & $5,69 \%$ \\
$2010-11$ & 864 & $-13,28 \%$ & $11,32 \%$ & 93 & $10,76 \%$ & 46 & $5,32 \%$ & 40 & $4,63 \%$ & 27 & $3,13 \%$ \\
$2011-12$ & 945 & $1,00 \%$ & $9,84 \%$ & 245 & $25,93 \%$ & 165 & $17,46 \%$ & 40 & $4,23 \%$ & 30 & $3,17 \%$ \\
$2012-13$ & 1026 & $-12,36 \%$ & $7,24 \%$ & 173 & $16,86 \%$ & 108 & $10,53 \%$ & 22 & $2,14 \%$ & 10 & $0,97 \%$ \\
$2013-14$ & 1100 & $22,56 \%$ & $10,11 \%$ & 19 & $1,73 \%$ & 9 & $0,82 \%$ & 112 & $10,18 \%$ & 82 & $7,45 \%$ \\
\hline Total & 6592 & $168,77 \%$ & $205,08 \%$ & 888 & $13,47 \%$ & 572 & $8,68 \%$ & 513 & $7,78 \%$ & 347 & $5,26 \%$ \\
\hline
\end{tabular}

Nota. Os percentuais entre parênteses no cabeçalho da tabela são os níveis de significância dos alfas de Jensen. A hipótese nula para a apuração dos níveis de significância é de que o alfa de Jensen seja igual a zero. O retorno do Ibovespa foi apurado entre o primeiro dia útil de setembro de um ano e o último de agosto do ano seguinte. Os alfas de Jensen foram estimados conforme a Equação 1.

\section{Modelo de pontuação e sua eficácia}

A Tabela 3 traz os modelos de pontuação mais bem-sucedidos que se aplicaram a cinco anos amostrais fora da amostra, uma vez que foram estimados com os dados dos quatro anos amostrais precedentes. As variáveis binárias com os níveis mais baixos de significância foram retiradas uma de 
cada vez e em um procedimento interativo, até que só restassem coeficientes significativos ao nível de dez por cento ou menos. O objetivo de somar somente os coeficientes significativos para obtenção da pontuação norteou essa forma de programação do algoritmo estatístico. A variável Ret apresentou elevada correlação com Sharpe e não foi considerada.

Tabela 3

Modelos de Pontuação para Períodos Analisados (Fora da Amostra)

\begin{tabular}{|c|c|c|c|c|c|}
\hline \multirow[t]{2}{*}{ Coeficiente } & \multicolumn{5}{|c|}{ Período de aplicação } \\
\hline & 2009-10 & 2010-11 & 2011-12 & 2012-13 & 2013-14 \\
\hline \multirow[t]{2}{*}{ Intercepto } & $-3,91 * *$ & $-3,27 * *$ & $-3,79 * *$ & $-3,70^{* *}$ & $-3,31 * *$ \\
\hline & $(-3,65 * *)$ & $(-3,54 * *)$ & $(-3,88 * *)$ & $(-3,70 * *)$ & $(-3,44 * *)$ \\
\hline \multirow[t]{2}{*}{ Alav } & $0,53 * *$ & - & - & $0,33 * *$ & - \\
\hline & $(0,50 * *)$ & $(0,24)$ & $(0,14)$ & $(0,35 * *)$ & $(0,16)$ \\
\hline \multirow[t]{2}{*}{$\mathrm{BC}$} & $-0,90 * *$ & $-0,53 * *$ & $-0,48 * *$ & - & $-0,23 * *$ \\
\hline & $(-0,84 * *)$ & $\left(-0,52^{* *}\right)$ & $\left(-0,40^{* *}\right)$ & $(-0,16)$ & $(-0,18)$ \\
\hline \multirow[t]{2}{*}{ FIC } & $0,44 * *$ & $0,62 * *$ & $0,76^{* *}$ & $0,65^{* *}$ & $0,71 * *$ \\
\hline & $\left(0,45^{* *}\right)$ & $(0,60 * *)$ & $(0,72 * *)$ & $(0,64 * *)$ & $(0,67 * *)$ \\
\hline \multirow[t]{2}{*}{ Idade } & - & $-0,34 *$ & $-0,43 * *$ & $-0,41 * *$ & $-0,51 * *$ \\
\hline & $(-0,30)$ & $(-0,28)$ & $(-0,37 *)$ & $(-0,43 * *)$ & $(0,53 * *)$ \\
\hline \multirow[t]{2}{*}{ IQ } & - & $0,77 * *$ & $0,68 * *$ & $0,64 * *$ & $0,81 * *$ \\
\hline & $(-0,05)$ & $(0,69 * *)$ & $(0,64 * *)$ & $(0,62 * *)$ & $(0,76 * *)$ \\
\hline \multirow[t]{2}{*}{ Novo } & $1,09 * *$ & - & $0,66 * *$ & $0,85^{* *}$ & $0,87 * *$ \\
\hline & $(0,82 * *)$ & $(0,34)$ & $(0,61 * *)$ & $(0,88 * *)$ & $\left(0,91^{* *}\right)$ \\
\hline \multirow[t]{2}{*}{ Perf } & - & $0,44 * *$ & - & - & - \\
\hline & $(0,06)$ & $(0,44 * *)$ & $(0,21)$ & $(0,06)$ & $(0,10)$ \\
\hline \multirow[t]{2}{*}{ PL } & - & $-0,37 * *$ & - & - & - \\
\hline & $(-0,32)$ & $(-0,29)$ & $(-0,11)$ & $(0,16)$ & $(0,13)$ \\
\hline \multirow[t]{2}{*}{ Sharpe } & $1,55^{* *}$ & $1,12 * *$ & $1,23^{* *}$ & $1,47 * *$ & $1,27 * *$ \\
\hline & $(1,54 * *)$ & $(1,28 * *)$ & $(1,21 * *)$ & $(1,44 * *)$ & $(1,24 * *)$ \\
\hline $\mathrm{R}^{2}$ de McFadden & 0,08 & 0,11 & 0,09 & 0,10 & 0,11 \\
\hline Estatística LR & 61,24 & 152,86 & 123,43 & 234,24 & 296,34 \\
\hline Prob (LR) & 0,00 & 0,00 & 0,00 & 0,00 & 0,00 \\
\hline Obs. Dependente $=0$ & 1602 & 1971 & 2529 & 2834 & 3114 \\
\hline Obs. Dependente $=1$ & 96 & 204 & 191 & 359 & 459 \\
\hline
\end{tabular}

Nota. A variável dependente é binária e assume o valor 1 caso o FIA tenha gerado alfa de Jensen significativo, positivo ou negativo, ao nível de cinco por cento no ano amostral, e 0 no caso contrário. Os coeficientes de cada período são significativos ao nível de dez por cento ou menos para o modelo passo a passo. Os coeficientes entre parênteses se referem ao modelo inicial, sem a eliminação passo a passo de variáveis. Os diagnósticos relatados são exclusivamente para o modelo final, depois da remoção de algumas variáveis, ano a ano, mas os valores foram muito semelhantes aos do modelo inicial. As variáveis explicativas são também binárias e estão descritas com detalhes no Apêndice. As variáveis categóricas binárias indicam, quando assumem o valor 1, que o fundo está ass ociado a uma instituição financeira de grande porte ou banco comercial (BC), permite alavancagem (Alav), destina-se a investidores qualificados (IQ), investe em cotas de outros fundos (FIC), cobra taxa de performance (Perf) e é seu primeiro ano completo de operação (Novo). As demais variáveis categóricas binárias indicam que o patrimônio líquido do fundo (PL), sua idade (Idade), retorno (Ret) e Índice de Sharpe (Sharpe) no período anterior estavam acima da mediana da amostra. Os modelos foram estimados conforme a Equação 2. Todos os modelos foram estimados a partir dos quatro anos de observações do conjunto de variáveis de forma agregada (pooled) que antecedem o período (ano) de aplicação. A variável Ret não foi incluída porque se comporta analogamente a Sharpe, ou seja, tem alta correlação com a mesma. Estatística LR denota a estatística do teste de razão de verossimilhança (Likelihood Ratio).

** indica significância a cinco por cento do teste t para a hipótese nula de que o coeficiente seja igual a zero.

* indica significância a dez por cento do teste t. 
A variável dependente assumiu o valor 1 quando o FIA apresentou alfa de Jensen positivo e significativo ao nível de cinco por cento no ano amostral e zero no caso contrário. A Tabela 3 mostra que as variáveis que denotam o IS acima da mediana no período anterior (Sharpe) e a constituição como FIC foram as únicas presentes em todos os períodos de aplicação. Sharpe apresentou coeficientes maiores do que FIC em todos os períodos, sugerindo uma tendência de que os FIAs com ISs mais elevados em um período são os mais prováveis candidatos para apresentar alfa positivo e significativo no período seguinte. Essa nova evidência de persistência no modelo classificatório é consistente com a apresentada por Matos et al. (2015) e Oliviera e Souza (2015).

Como indicado na análise univariada, o vínculo com grandes instituições financeiras apresentou coeficientes negativos em todos os períodos em que houve significância. Os coeficientes significativos positivos de FIAs destinados a investidores qualificados corroboram as conclusões de Sanematsu (2013), que defendeu que os desalinhamentos de interesse entre o gestor e o investidor são menores nesses FIAs. Os modelos sugerem que é mais provável que FIAs novos alcancem alfas positivos, o que é consistente com a evidência exploratória de Matos et al. (2015). Finalmente, os modelos também indicam, de forma menos contundente, que o uso da alavancagem está diretamente relacionado com a chance de geração de alfa. A indicação de uso de alavancagem implica o emprego de instrumentos derivativos, que podem ser usados tanto para aumentar o potencial de ganho com aumento correspondente de risco (a alavancagem propriamente dita) quanto de forma defensiva, como hedge para reduzir a volatilidade, preservando o potencial de alcançar retornos atraentes, o que, de certa forma, é consistente com o modelo de Oliviera e Souza (2015) e as conclusões de Santiago e Leal (2015). Naturalmente, não se pode afirmar se tais instrumentos foram usados para alavancagem ou proteção, e não se pode saber o tipo de uso que influenciou os resultados. Os resultados da Tabela 3 são consistentes com os relatados nas análises univariadas da Tabela 1. Os coeficientes do modelo inicial, sem eliminação de quaisquer variáveis explicativas, também mostrados na Tabela 3, são plenamente consistentes com os coeficientes finais. O procedimento stepwise contribuiu para simplificar a apuração da pontuação, com a soma exclusiva dos coeficientes significativos a cada ano, sem, contudo, alterar substancialmente os resultados indicados no modelo original.

A Tabela 4 oferece evidência acerca da eficácia do modelo de pontuação final da Tabela 3. O modelo de pontuação parece oferecer uma oportunidade para que o investidor selecione FIAs que terão bom desempenho no período seguinte e, talvez com maior probabilidade ainda, não escolha FIAs que levem a resultados desastrosos, com alfas significativamente negativos.

Tabela 4

Quantidade de FIAs com Alfa de Jensen Significativos

\begin{tabular}{lllllllllll}
\hline $\begin{array}{l}\text { Período de } \\
\text { Aplicação }\end{array}$ & Grupo & Total de & Alfa $>0(10 \%)$ & Alfa $>0(5 \%)$ & Alfa $<0(10 \%)$ & Alfa $<0(5 \%)$ \\
\hline $2009-10$ & TIAs & & & & & & & & & \\
& Todos os FIAs & 738 & $169^{*}$ & $22,90 \%$ & $129^{*}$ & $17,48 \%$ & 78 & $10,57 \%$ & 42 & $5,69 \%$ \\
& 100 melhores & 132 & $60^{*}$ & $45,45 \%$ & $47^{*}$ & $35,61 \%$ & $5^{*}$ & $3,79 \%$ & 3 & $2,27 \%$ \\
& Maior pontuação & 46 & $33^{*}$ & $71,74 \%$ & $24 *$ & $52,17 \%$ & $0^{*}$ & $0,00 \%$ & $0 *$ & $0,00 \%$ \\
\hline $2010-11$ & Todos os FIAs & 864 & 93 & $10,76 \%$ & 46 & $5,32 \%$ & $40^{*}$ & $4,63 \%$ & 27 & $3,13 \%$ \\
& 100 melhores & 100 & 14 & $14,00 \%$ & 7 & $7,00 \%$ & $2^{*}$ & $2,00 \%$ & 2 & $2,00 \%$ \\
& Maior pontuação & 20 & $3^{*}$ & $15,00 \%$ & $0^{*}$ & $0,00 \%$ & 2 & $10,00 \%$ & $2 *$ & $10,00 \%$ \\
\hline \multirow{2}{2011-12}{} & Todos os FIAs & 945 & $245^{*}$ & $25,93 \%$ & $165^{*}$ & $17,46 \%$ & $40^{*}$ & $4,23 \%$ & 30 & $3,17 \%$ \\
& 100 melhores & 123 & $66^{*}$ & $53,66 \%$ & $44^{*}$ & $35,77 \%$ & $0^{*}$ & $0,00 \%$ & $0 *$ & $0,00 \%$ \\
& Maior pontuação & 45 & $23^{*}$ & $51,11 \%$ & $16^{*}$ & $35,56 \%$ & $0^{*}$ & $0,00 \%$ & $0 *$ & $0,00 \%$ \\
\hline
\end{tabular}




\section{Tabela 4 (continuação)}

\begin{tabular}{|c|c|c|c|c|c|c|c|c|c|c|}
\hline \multirow{2}{*}{$\begin{array}{l}\text { Período de } \\
\text { Aplicação }\end{array}$} & \multirow{2}{*}{$\begin{array}{l}\text { Grupo } \\
\text { Todos os FIAs }\end{array}$} & \multirow{2}{*}{$\begin{array}{l}\text { Total de } \\
\text { FIAs } \\
1026\end{array}$} & \multicolumn{2}{|c|}{ Alfa $>0(10 \%)$} & \multicolumn{2}{|c|}{ Alfa $>0(5 \%)$} & \multicolumn{2}{|c|}{ Alfa $<0(10 \%)$} & \multicolumn{2}{|c|}{ Alfa $<0(5 \%)$} \\
\hline & & & $173^{*}$ & $16,86 \%$ & $108 *$ & $10,53 \%$ & $22 *$ & $2,14 \%$ & $10 *$ & $0,97 \%$ \\
\hline & 100 melhores & 113 & $41 *$ & $36,28 \%$ & $26^{*}$ & $23,01 \%$ & $0^{*}$ & $0,00 \%$ & $0 *$ & $0,00 \%$ \\
\hline & Maior pontuação & 55 & $23 *$ & $41,82 \%$ & $14 *$ & $25,45 \%$ & $0 *$ & $0,00 \%$ & $0 *$ & $0,00 \%$ \\
\hline \multirow[t]{3}{*}{ 2013-14 } & Todos os FIAs & 1100 & $19 *$ & $1,73 \%$ & 9 & $0,82 \%$ & 112 & $10,18 \%$ & 82 & $7,45 \%$ \\
\hline & 100 melhores & 146 & $2 *$ & $1,37 \%$ & 2 & $1,37 \%$ & $1 *$ & $0,68 \%$ & $1 *$ & $0,68 \%$ \\
\hline & Maior pontuação & 71 & $2 *$ & $2,82 \%$ & $2 *$ & $2,82 \%$ & $0 *$ & $0,00 \%$ & $0 *$ & $0,00 \%$ \\
\hline
\end{tabular}

Nota. Os percentuais entre parênteses no cabeçalho da tabela são os níveis de significância dos alfas de Jensen. Os percentuais da tabela são a razão entre a quantidade de FIAs com alfa de Jensen significativo e o total de FIAs em cada grupo. 100 melhores se refere aos 100 FIAs que obtiveram as maiores pontuações nos modelos estimados segundo a Equação 2 nos respectivos períodos. O total de FIAs desse grupo pode ser maior do que 100 porque houve empates com o $100^{\circ}$ FIA. Maior pontuação se refere aos FIAs que lograram a maior pontuação em cada período de aplicação. O total de FIAs desse grupo é maior do que um porque houve empates na maior pontuação.

* denota significância ao nível de cinco por cento para a probabilidade da distribuição binomial com cinco ou dez por cento de chance de sucesso para alfas significativos a cinco ou dez por cento, respectivamente. A hipótese nula neste caso iguala o alfa de Jensen a zero.

O resultado que indica que o desempenho passado é um bom preditor do desempenho futuro no mercado brasileiro não é novo na literatura, pois Santiago e Leal (2015) e Carneiro e Leal (2015), por exemplo, concluem que uma carteira $1 / \mathrm{N}$ com dez ações componentes do Ibovespa selecionadas segundo os maiores ISs no quadrimestre anterior e rebalanceada quadrimestralmente é uma boa opção para o investidor individual brasileiro aplicar em ações. Os autores alegam comparações favoráveis dessas carteiras em relação aos FIAs. A Tabela 5 retorna a este tipo de comparação com uma amostra muito maior de fundos. Ela mostra o contraste entre grupos de FIAs, incluindo os de melhor pontuação, e a carteira $1 / \mathrm{N}$ formada tal como Carneiro e Leal (2015) sugerem. Finalmente, cabe notar que a escolha por um modelo composto somente por variáveis categóricas binárias levou a um número grande de empates nas classificações.

Tabela 5

Quantidade de FIA da Amostra que Superaram a Carteira 1/N

\begin{tabular}{|c|c|c|c|c|c|c|}
\hline \multirow{2}{*}{ Período } & \multirow{2}{*}{ Grupo } & \multirow{2}{*}{ Total de FIAs } & \multicolumn{4}{|c|}{$\mathrm{N}^{\circ}$ de FIAs que superaram a carteira $1 / \mathrm{N}$} \\
\hline & & & Em retorno & & Em IS & \\
\hline 2004-05 & Todos os FIAs & 221 & $123^{*}$ & $55,66 \%$ & $172 *$ & $77,83 \%$ \\
\hline 2005-06 & Todos os FIAs & 261 & $229^{*}$ & $87,74 \%$ & $238^{*}$ & $91,19 \%$ \\
\hline 2006-07 & Todos os FIAs & 319 & 146 & $45,77 \%$ & $253^{*}$ & $79,31 \%$ \\
\hline 2007-08 & Todos os FIAs & 472 & $296^{*}$ & $62,71 \%$ & $271 *$ & $57,42 \%$ \\
\hline 2008-09 & Todos os FIAs & 646 & $20 *$ & $3,10 \%$ & $32 *$ & $4,95 \%$ \\
\hline \multirow[t]{3}{*}{$2009-10$} & Todos os FIAs & 738 & $298^{*}$ & $40,38 \%$ & $411 *$ & $55,69 \%$ \\
\hline & 100 melhores & 132 & $81^{*}$ & $61,36 \%$ & $104 *$ & $78,79 \%$ \\
\hline & Maior pontuação & 46 & $35^{*}$ & $76,09 \%$ & $44 *$ & $95,65 \%$ \\
\hline
\end{tabular}

Continua 
Tabela 5 (continuação)

\begin{tabular}{|c|c|c|c|c|c|c|}
\hline \multirow{2}{*}{ Período } & \multirow{2}{*}{ Grupo } & \multirow{2}{*}{ Total de FIAs } & \multicolumn{4}{|c|}{$\mathrm{N}^{\mathrm{o}}$ de FIAs que superaram a carteira $1 / \mathrm{N}$} \\
\hline & & & Em retorno & & Em IS & \\
\hline \multirow[t]{3}{*}{ 2010-11 } & Todos os FIAs & 864 & $67 *$ & $7,75 \%$ & $77 *$ & $8,91 \%$ \\
\hline & 100 melhores & 100 & $24 *$ & $24,00 \%$ & $27^{*}$ & $27,00 \%$ \\
\hline & Maior pontuação & 20 & $6^{*}$ & $30,00 \%$ & $7 *$ & $35,00 \%$ \\
\hline \multirow[t]{3}{*}{ 2011-12 } & Todos os FIAs & 945 & $247^{*}$ & $26,14 \%$ & $328^{*}$ & $34,71 \%$ \\
\hline & 100 melhores & 123 & $60^{*}$ & $48,78 \%$ & $85^{*}$ & $69,11 \%$ \\
\hline & Maior pontuação & 45 & $19 *$ & $42,22 \%$ & $28 *$ & $62,22 \%$ \\
\hline \multirow[t]{3}{*}{ 2012-13 } & Todos os FIAs & 1026 & $397 *$ & $38,69 \%$ & $400^{*}$ & $38,99 \%$ \\
\hline & 100 melhores & 113 & $92 *$ & $81,42 \%$ & $97 *$ & $85,84 \%$ \\
\hline & Maior pontuação & 55 & $43^{*}$ & $78,18 \%$ & $47 *$ & $85,45 \%$ \\
\hline \multirow[t]{3}{*}{ 2013-14 } & Todos os FIAs & 1100 & $145^{*}$ & $13,18 \%$ & 571 & $51,91 \%$ \\
\hline & 100 melhores & 146 & $17 *$ & $11,64 \%$ & $106^{*}$ & $72,60 \%$ \\
\hline & Maior pontuação & 71 & $14 *$ & $19,72 \%$ & $50 *$ & $70,42 \%$ \\
\hline
\end{tabular}

Nota. IS significa Índice de Sharpe calculado na forma tradicional indicada no Apêndice (Sharpe), sem o ajuste proposto por Israelsen, C. L. (2005). A refinement to the Sharpe ratio and information ratio. Journal of Asset Management, 5(6), 423-427. http://dx.doi.org/10.1057/palgrave.jam.2240158. Carteiras 1/N segundo Carneiro, A. A., \& Leal, R. P. C. (2015). Seleção de ações, carteiras de ponderação igualitária e fundos de investimento em ações no Brasil [Relatórios Coppead, 424]. Rio de Janeiro, RJ, Brail, Instituto COPPEAD de Administração, Universidade Federal do Rio de Janeiro. Os percentuais se referem às razões entre o número de FIAs que superaram a carteira $1 / \mathrm{N}$ e o número de FIAs ativos para cada período e grupo. A carteira $1 / \mathrm{N}$ é igualmente ponderada e composta por dez ações do índice Ibovespa selecionadas segundo os maiores ISs no quadrimestre anterior e rebalanceada quadrimestralmente. As pontuações foram obtidas da aplicação do modelo proposto na Equação 2 cujos coeficientes estão retratados na Tabela 4. 100 melhores se refere aos 100 FIAs que obtiveram as maiores pontuações nos modelos estimados segundo a Equação 2 nos respectivos períodos. O total de observações desse grupo pode ser maior do que 100 porque houve empates com o $100^{\circ}$ FIA. Maior pontuação se refere aos FIAs que lograram a maior pontuação em cada período de aplicação. O total de observações é maior do que um porque houve empates na maior pontuação.

* denota significância ao nível de 5\% para a probabilidade da distribuição binomial com $50 \%$ de chance de sucesso, tendo como hipótese nula que o retorno médio dos FIAs iguala o retorno médio das respectivas carteiras 1/N.

Em linhas gerais, percebe-se novamente que maiores pontuações tendem a gerar resultados melhores também quando comparados com resultados da carteira igualmente ponderada. A estratégia de investimento igualmente ponderada, contudo, é atraente para o investidor individual quando comparada à amostra completa de FIAs. Esse resultado realça a importância da seleção do FIA para o investidor individual. $\mathrm{O}$ modelo de pontuação parece ser mais bem-sucedido em relação ao IS do que quanto ao retorno, ressalvado que esta métrica foi calculada na forma tradicional, sem o ajuste proposto por Israelsen (2005), não oferecendo o ordenamento correto quando negativa, mas optou-se por mantêla assim para que seus resultados sejam consistentes com os obtidos com o retorno. Esse resultado é compatível com o que foi observado por Santiago e Leal (2015) e Carneiro e Leal (2015) para uma amostra de FIAs sobreviventes, pois sugere que os gestores dos FIAs podem estar preocupados com a redução da volatilidade, enquanto um investidor que segue uma regra simples de formação de carteiras não executa nenhum procedimento ativo para limitar a volatilidade. Ademais, carteiras igualmente ponderadas com poucas ações não são bem diversificadas e seu retorno maior pode ser simplesmente reflexo de sua exposição a fatores de risco adicionais, tais como os empregados por Carhart (1997). 


\section{Conclusões}

O modelo de pontuação proposto indica que o desempenho passado, medido pelo Índice de Sharpe (IS) acima da mediana em períodos anteriores, foi a variável que apresentou o maior coeficiente, sendo, portanto, a característica mais importante para discriminar FIAs com alfa de Jensen significativo ao nível de cinco por cento (fora da amostra). Lembra-se que todos os coeficientes são comparáveis porque estão na mesma escala, uma vez que todas as variáveis explicativas do modelo são categóricas binárias. Além disso, tal variável se mostrou estatisticamente significativa em todos os períodos de análise fora da amostra. O estudo revela que há alguma persistência no desempenho dos gestores mais bemsucedidos, tal como sugerido por Oliviera e Souza (2015). O retorno ajustado ao risco (IS) passado como característica mais importante também pode ser um indício de que os gestores dos FIAs se preocupam com a limitação da volatilidade e que, entre eles, há aqueles que logram retornos atraentes e geram alfa mesmo quando limitam suas exposições ao risco.

O presente artigo traz contribuições inéditas porque propõe um procedimento de pontuação com um amplo conjunto de variáveis categóricas (e binárias) que retratam os FIAs em uma amostra de 1.417 fundos, na qual foram incluídos fundos iniciados ou encerrados durante o período amostral, mitigando o viés de sobrevivência. O modelo de pontuação proposto considerou mais oito características dos FIAs, além do desempenho passado. Esse conjunto de características é mais amplo do que outros empregados na literatura nacional. Os resultados do modelo proposto apontam que FIAs iniciantes (primeiro ano completo de divulgação de cotas) ou pouco longevos, a gestão independente (desvinculada de grandes instituições financeiras), o direcionamento para investidores qualificados e a constituição segundo um FIC podem ser características importantes para distinguir um FIA com alfa de Jensen positivo e significativo no período seguinte. Os resultados para a longevidade são análogos aos da análise exploratória de Matos et al. (2015). A evidência para a autorização para o uso de alavancagem foi fraca, sendo de certa forma consistente com sua ausência na versão final do modelo de Oliviera e Souza (2015). Os resultados para as demais características, porém, aparentam ser inéditos na literatura nacional.

As estimativas do modelo mostram, ainda, que a cobrança de taxa de performance e o tamanho do FIA, medido por seu patrimônio líquido (PL), apresentam coeficiente significativo em apenas um ano. A falta de significância do PL é consistente com a evidência de Milani e Ceretta (2012), pois o PL não foi elemento capaz de discriminar entre FIAs de gestão ativa com alfa positivo e negativo para estes autores. O resultado para a taxa de performance contradiz a evidência em Oliviera e Souza (2015) e Matos et al. (2015). É possível que a amostra muito maior e com pouca influência do viés de sobrevivência aqui empregada, apresentando um conjunto mais amplo de características contempladas dos FIAs, tenha revelado que a presença da taxa de performance seja dominada por outras características, tal como o direcionamento para investidores qualificados e a gestão independente.

O modelo de pontuação proposto pode permitir que o investidor selecione FIAs que não terão desempenho catastrófico (alfa de Jensen negativos e significativos). A pontuação do modelo também estava associada à escolha de FIAs com alfas positivos e significativos em maior proporção do que na amostra com todos os FIAs em praticamente todos os períodos contemplados.

O estudo também contribui ao contrastar os FIAs mais bem pontuados com carteiras igualmente ponderadas, trazendo o foco para o investidor individual menos sofisticado e sua escolha entre um FIA e gerir sua própria carteira. A carteira de ponderação igualitária de dez ações constituintes do Ibovespa selecionadas pelo maior IS no quadrimestre anterior e rebalanceada quadrimestralmente foi a forma escolhida e considerou custos de transação. Os FIAs com a maior pontuação superaram a carteira 1/N em termos do IS em testes fora da amostra em quatro dos cinco períodos analisados. Estes resultados, contudo, não eliminam a atratividade da carteira de ponderação igualitária porque seu retorno ainda foi maior do que mais da metade dos FIAs de maior pontuação em dois dos cinco períodos avaliados. Mais uma vez é importante notar que os FIAs se saem melhor quando a volatilidade é considerada, como no caso do IS. Houve alguma evidência de que a alavancagem possa ser empregada para reduzir a volatilidade. Os gestores parecem se preocupar, de forma geral, com a gestão da volatilidade. Esses 
resultados contrastam com os de Santiago e Leal (2015), entre outros, porque estes autores compararam o desempenho da carteira 1/N a uma amostra de FIAs de gestão ativa sobreviventes e não somente aos de melhor desempenho. Sendo assim, conclusões de outros trabalhos sobre a atratividade da carteira 1/N ainda se sustentam quando se considera o universo de FIAs.

Uma limitação óbvia desse estudo é o número de períodos fora da amostra investigados (cinco). Naturalmente, quanto mais períodos, melhor. Deve-se lembrar das conclusões de Cuthbertson et al. (2016) e Chen et al. (2016) para a literatura internacional de que é muito difícil escolher um fundo bemsucedido ex-ante e que a persistência pode durar pouco. Uma alternativa para mitigar o problema poderia ser o emprego de técnicas de simulação (ex.: bootstrapping), tal como em Laes e Silva (2015). É possível que, como apontaram estes autores, a proporção de FIAs com alfas de Jensen positivos e significativos ainda seja elevada em função da sorte de alguns gestores, particularmente quando se emprega uma amostra grande. Contudo, como o foco aqui não estava na questão da sorte ou da habilidade do gestor, o que realmente importa para o investidor é se conseguiu um retorno atraente.

Há uma evidente inversão na relação entre rentabilidade e as características dos FIAs nos períodos 2004-05, 2007-08 e 2013-14 Essa inversão pode ser reflexo, dentre outros fatores, das características, tal como a liquidez, e dos pesos dos ativos mantidos em carteira por cada tipo de FIA. Estudos futuros poderiam considerar essas características, bem como o estilo declarado pelo gestor (long and short, small caps, long only, etc.) e o grau de semelhança com um índice escolhido como representativo da carteira de mercado.

Ceretta e Costa (2001) ilustraram o uso da análise por envoltória de dados e múltiplos atributos de fundos, mas só empregaram a taxa de administração entre as características dos FIAs. É possível que investigações futuras queiram retornar a essa técnica e empregá-la junto com os diversos atributos aqui considerados, como alternativa ao modelo de regressão logística. Finalmente, cabe dizer que o modelo empregado não pretende reproduzir o processo decisório de um investidor em particular. Ele apenas indica quais são as variáveis mais importantes para a identificação de um FIA com bom desempenho ajustado ao risco a partir de um conjunto de variáveis que integram o banco de dados consultado e que foram consideradas ao alcance do entendimento de um investidor individual.

\section{Referências}

Argolo, E. F. B., Leal, R. P. C., \& Almeida, V. S. (2012). O modelo de Fama e French é aplicável no Brasil? [Relatórios Coppead, 402]. Rio de Janeiro, RJ, Brasil, Instituto COPPEAD de Administração, Universidade Federal do Rio de Janeiro.

Associação Brasileira das Entidades do Mercado Financeiro e de Capitais. (2016). Consolidado histórico de fundos. São Paulo, SP: Autor. Recuperado de http://goo.gl/J8pnjT

BM\&FBOVESPA. (2015). Metodologia do índice Bovespa. São Paulo, SP: Autor.

Carhart, M. M. (1997). On persistence in mutual fund performance. Journal of Finance, 52(1), 57-82. http://dx.doi.org/10.1111/j.1540-6261.1997.tb03808.x

Carneiro, A. A., \& Leal, R. P. C. (2015). Seleção de ações, carteiras de ponderação igualitária e fundos de investimento em ações no Brasil (Relatórios Coppead, 424). Rio de Janeiro, RJ, Brasil, Instituto COPPEAD de Administração, Universidade Federal do Rio de Janeiro.

Castro, B. R., \& Minardi, A. M. A. F. (2009). Comparação do desempenho dos fundos de ações ativos e passivos. Revista Brasileira de Finanças, 7(2), 143-161.

Ceretta, P. S., \& Costa, N. C. A., Jr. (2001). Avaliação e seleção de fundos de investimento: um enfoque sobre múltiplos atributos. Revista de Administração Contemporânea, 5(1), 7-22. Recuperado de 
http://www.scielo.br/pdf/rac/v5n1/v5n1a02.pdf.

http://dx.doi.org/10.1590/S141565552001000100002

Chen, H.-C., Lai, C. W., \& Wu, S.-C. (2016). Mutual fund selection and performance persistence in 401(k) plans. North American Journal of Economics and Finance, 35(1), 78-100. http://dx.doi.org/10.1016/j.najef.2015.10.004

Cuthbertson, K., Nitzsche, D., \& O'Sullivan, N. (2016). A review of behavioral and management effects in mutual fund performance. International Review of Financial Analysis, 44(1), 162-176. http://dx.doi.org/10.1016/j.irfa.2016.01.016

Fama, E. F., \& French, K. R. (1993). Common risk factors in the returns on stocks and bonds. Journal of Financial Economics, 33(1), 3-56. http://dx.doi.org/10.1016/0304-405X(93)90023-5

Fama, E. F., \& French, K. R. (2010). Luck versus skill in the cross-section of mutual fund returns. The Journal of Finance, 65(5), 1915-1947. http://dx.doi.org/10.1111/j.1540-6261.2010.01598.x

Iquiapaza, R. A. (2009). Performance, captação e foco das famílias de fundos de investimento (Tese de doutorado). Universidade Federal de Minas Gerais, Belo Horizonte, MG, Brasil.

Israelsen, C. L. (2005). A refinement to the Sharpe ratio and information ratio. Journal of Asset Management, 5(6), 423-427. http://dx.doi.org/10.1057/palgrave.jam.2240158

Jagannathan, R., Malakhov, A., \& Novikov, D. (2010). Do hot hands exist among hedge fund managers? An empirical evaluation. The Journal of Finance 56(1), 217-255. http://dx.doi.org/10.1111/j.1540-6261.2009.01528.x

Laes, M. A., \& Silva, M. E. (2015). Performance of mutual equity funds in Brazil - a bootstrap analysis. Economia, 15(3), 294-306. http://dx.doi.org/10.1016/j.econ.2014.08.002

Matos, P. R. F., Linhares, F. C., \& Sylvestre, G. Z. (2012). Análise do efeito não linear do patrimônio líquido no apreçamento de fundos de investimento em ações. Brazilian Business Review, 9(4), 127. http://dx.doi.org/10.15728/bbr.2012.9.4.1

Matos, P. R. F., Penna, C. M., \& Silva, A. B. G. (2015). Fundos mútuos de investimento em ações no Brasil: incentivos, gestão e convergência. Brazilian Business Review, 12(2), 115-147. http://dx.doi.org/10.15728/bbr.2015.12.2.6

Matos, P. R. F., \& Rocha, J. A. T. (2009). Ações e fundos de investimento em ações: fatores de risco comuns? Brazilian Business Review, 6(1), 22-43. http://dx.doi.org/10.15728/bbr.2009.6.1.2

Milani, B., \& Ceretta, P. S. (2012). Tamanho e rentabilidade dos fundos brasileiros de investimento em ações. Revista Alcance - Eletrônica, 19(4), 461-475. Recuperado de http://siaiap32.univali.br/seer/index.php/ra/article/download/2257/2445. http://dx.doi.org/10.14210/alcance.v19n4.p461-475

Oliviera, B. G., \& Souza, A. F. (2015). Fundos de investimento em ações no Brasil: métricas para avaliação de desempenho. Revista de Gestão, 22(1), 41-56. http://dx.doi.org/10.5700/rege550

Sanematsu, F. C. (2013). Remuneração dos gestores, público alvo e conflitos de interesse em fundos de ações no Brasil. Economia Aplicada, 17(3), 267-298. http://dx.doi.org/10.1590/S141380502013000300003

Sanematsu, F. C. (2014). Dois ensaios sobre fundos de investimentos em ações no Brasil (Tese de doutorado). Universidade Federal do Rio de Janeiro, Rio de Janeiro, RJ, Brasil. 
Santiago, D. C., \& Leal, R. P. C. (2015). Carteiras igualmente ponderadas com poucas ações e o pequeno investidor. Revista de Administração Contemporânea, 19(5), 544-564. http://dx.doi.org/10.1590/1982-7849rac20151794

Sharpe, W. F. (1994). The Sharpe ratio. Journal of Portfolio Management, 21(1), 49-58. http://dx.doi.org/10.3905/jpm.1994.409501

Sortino, F. A., \& Price, L. N. (1994). Performance measurement in a downside risk framework. The Journal of Investing, 3(3), 59-64. http://dx.doi.org/10.3905/joi.3.3.59

Varga, G. (2001). Índice de Sharpe e outros indicadores de performance aplicados a fundos de ações brasileiros. Revista de Administração Contemporânea, 5(3), 215-245. Recuperado de http://www.scielo.br/pdf/rac/v5n3/v5n3a11.pdf. 65552001000300011

Varga, G., \& Wengert, M. (2011). A indústria de fundos de investimentos no Brasil. Revista de Economia e Administração, 10(1), 66-109.

\section{Dados dos Autores}

João Antonio de Mendonça Júnior

Praia do Flamengo, 66, 22210-030, Rio de Janeiro, RJ, Brasil. E-mail: mendonca.ime@ gmail.com

Carlos Heitor Campani

Rua Pascoal Lemme, 355, Cidade Universitária, 21941-918, Rio de Janeiro, RJ, Brasil. E-mail: carlos.heitor@ coppead.ufrj.br

Ricardo Pereira Câmara Leal

Rua Pascoal Lemme, 355, Cidade Universitária, 21941-918, Rio de Janeiro, RJ, Brasil. E-mail: ricardoleal@coppead.ufrj.br 


\section{APÊNDICE}

\section{Definição das Variáveis}

\begin{abstract}
Variável Definição das variáveis
$\mathrm{BC} \quad$ Igual a 1 para gestores vinculados às seguintes instituições financeiras: Bradesco; Citibank; Banco do Nordeste do Brasil (BNB); Banco Itaucard; Banrisul; BB Gestão de Recursos DTVM; BNP Paribas Asset Management; Bradesco Asset Management; BTG Pactual Gestora de Recursos; BTG Pactual WM Gestão de Recursos; Caixa Econômica Federal; Credit Suisse Corretora; Credit Suisse HedgingGriffo; Goldman Sachs Banco Múltiplo; HSBC Global Asset Management; Itaú DTVM; Itaú Unibanco; J Safra Asset Management; JP Morgan Asset Management; Santander Brasil Asset Management; UBS Brasil; Unibanco Asset Management; Votorantim Asset Management. Assume 0 para os demais gestores. É esperado que os FIAs geridos por gestores vinculados a grandes instituições financeiras, particularmente aquelas com clientes de bancos comerciais, possuam menores retornos e volatilidades que os demais, devido à crença de que um grande banco não arriscaria desvalorizar sua marca, ou sofrer muitos saques de clientes ao gerir um fundo muito agressivo, o que talvez não fosse problema para um gestor independente. A importância da natureza da instituição gestora no Brasil foi apontada por Sanematsu (2013, 2014) e Matos et al. (2015).
\end{abstract}

PL Assume o valor 1 quando o patrimônio líquido médio no período anterior estiver acima da mediana, e 0 no caso contrário ou se o fundo é novo. Não é esperada uma clara relação entre o patrimônio líquido e os resultados, uma vez que os melhores FIAs tendem a atrair mais investimentos, mas ao mesmo tempo um patrimônio líquido muito elevado torna mais difícil a manutenção dos retornos que seriam obtidos com menos ativos sob gestão. Chen et al. (2016), Castro e Minardi (2009), Milani e Ceretta (2012) e Matos et al. (2012) consideram o tamanho do fundo em suas análises.

Idade Assume o valor 1 quando a longevidade (isto é, a idade) no período anterior estiver acima da mediana, e 0 no caso contrário ou se o fundo é novo. Cuthbertson et al. (2016), Sanematsu (2013, 2014), Matos et al. (2015) e Milani e Ceretta (2012) apontam a importância da idade do fundo em relação a seu desempenho.

Alav Assume o valor 1 se o regulamento do fundo permite alavancagem, e 0 no caso contrário. É esperado que um fundo alavancado possua uma maior volatilidade nos retornos. Os fundos alavancados podem não ser atraentes para o investidor se não houver retorno proporcional a esse risco maior. É importante salientar que a classificação do FIA como alavancado não implica necessariamente o uso dessa técnica, pois a gestão do fundo pode optar por não empregá-la, mesmo quando autorizado por seu regulamento. Oliviera e Souza (2015) empregaram esta variável em seu modelo de classificação de desempenho de FIAs.

IQ Assume o valor 1 se for destinado a investidores qualificados, e 0 no caso contrário. Investidores qualificados são as pessoas físicas e jurídicas com investimentos superiores a $R \$ 300.000,00$ e que atestam esta condição por escrito. Ver a Instrução CVM n 409 para a lista completa das entidades consideradas como investidores qualificados. É importante verificar se os indícios de diferentes graus de desalinhamento entre os interesses dos gestores e os diferentes tipos de cotistas, apontados por Sanematsu (2013), se refletem persistentemente no histórico da rentabilidade dos FIAs.

FIC Assume o valor 1 se for fundo de investimento em cotas (FIC), e 0 no caso contrário. Com esta segregação, desejou-se verificar se há indícios de que a estrutura master-feeder é capaz de gerar ganhos de escala ou de diversificação, quando os FICs geram valor para os cotistas pela aplicação em cotas de outros fundos. Aspectos consistentes com esta estrutura, tais como as famílias de fundos, foram estudas por Chen et al. (2016) e Iquiapaza (2009).

Perf Assume o valor 1 se cobrar taxa de performance, e 0 se não cobrar. Verifica-se a correlação entre a cobrança desta taxa e o retorno líquido do fundo, o que pode indicar que os melhores gestores a usem para capturar parte do valor gerado para os cotistas pela gestão ativa. Cuthbertson et al. (2016), Matos et al. (2015), Oliviera e Souza (2015) e Sanematsu $(2013,2014)$ estão entre os autores que apontam a importância desta variável. 
Ret Assume o valor 1 se o retorno no período anterior se situou acima da mediana de todos os fundos no
referido período, e 0 no caso contrário ou se o fundo é novo. Retornos passados elevados talvez sejam
a característica mais usada por novos investidores para inferir sobre a possibilidade futura de geração
de alfa. A importância do desempenho passado foi apontada por Cuthbertson et al. (2016), Chen et al.
(2016), Matos et al. (2015), Oliviera e Souza (2015) e Jagannathan et al. (2010), entre outros.

Sharpe Assume o valor 1 se o índice de Sharpe no período anterior se situou acima da mediana de todos os fundos no referido período, e 0 no caso contrário ou se o fundo é novo. O Índice de Sharpe (ex-post) foi calculado, com observações diárias, tal como em Varga (2001):

$$
I S=\frac{R_{p}-R_{f}}{\sigma_{p}}
$$

Onde: $R_{p}=$ retorno diário líquido médio do FIA $p ; R_{f}=$ taxa média de retorno diário do ativo livre de risco (CDI) e $\sigma_{p}=$ desvio-padrão do excesso de retorno do FIA $p$ em relação ao ativo livre de risco. Não foram feitos ajustes ao IS quando seu numerador era negativo, uma vez que ele foi transformado na variável categórica binária Sharpe, sendo o correto ordenamento de ISs negativos pouco importante para a obtenção desta variável. Esta categoria leva em consideração se o fato de haver gestor capaz de gerar retornos elevados com baixa volatilidade em um período pode criar valor para o cotista no período subsequente. O IS passado foi usado em Chen et al. (2016), Matos et al. (2015) e Oliviera e Souza (2015), entre outros.

Novo Assume o valor 1 se o fundo é novo, e 0 no caso contrário. Um FIA é considerado novo em um período caso esta seja a primeira vez que o fundo divulgou cotas do início ao fim do período. Esta variável foi sugerida pelas evidências em Sanematsu $(2013,2014)$ e Matos et al. (2015). 